\title{
Research on the Response of School and Teachers to Bullying
}

\author{
Zilu Zhang ${ }^{1, *}$ \\ ${ }^{I}$ School of Education, University of Sheffield, Sheffield S10 2GW, South Yorkshire, United Kingdom \\ *Corresponding author.eduug@sheffield.ac.uk
}

\begin{abstract}
School bullying, as a phenomenon of campus violence, is a long-term and frequent threat to the physical and mental health of young people. This is a purposeful attack, which usually occurs between students with unequal strength. It refers to the injury behavior of a person or group of people to the bullied. School bullying has been staged all over the world, but the boundary definition of bullying is still unclear, and there is a lack of relevant management methods. Since around the 1970s, scholars have gradually begun to formally study the issues of related events, and various countries have successively issued policies for campus bullying. This paper is a literature review article, which analyzes the current situation and prevention measures of school bullying from five parts: the harm of school bullying, the impact of bullying on schools, the reactions of teachers and students, and relevant policies. It mainly discusses the different reactions of teachers, employees, and students when they hear about school bullying. Through the existing research cases, this paper analyzes teachers' cognition and attitude towards bullying and puts forward the problem of clarifying the definition of the boundary of bullying events before taking preventive intervention measures. This paper also expounds on the negative impact of school bullying and the current anti-bullying policy and puts forward some suggestions for the improvement of future policy.
\end{abstract}

Keywords: School bullying, teacher response, student response, the anti-bullying policy

\section{INTRODUCTION}

School bullying is a violent phenomenon that occurs in schools. This phenomenon has been threatening the physical and mental health of students since many years ago, and people did not pay enough attention to it at that time. Until around the 1970 s, scholars began to pay attention to this issue. The formal research on school bullying began with the Norwegian psychologist Dan Olweus, who is known as the pioneer and founder of this research [1]. He thought that school bullying usually refers to a student who repeats it over a long period of time by one or more students and that this is usually a chronic and frequent incident. Bullying is intentional offensive behavior, which exists in many forms, including but not limited to violence, cyberbullying, and verbal bullying. At present, school bullying incidents are staged almost every day in different countries around the world. Some students have been targeted for bullying and suffered deliberate acts of injury by others, resulting in physical and psychological harm. However, in some more remote areas, schools and teachers pay less attention to the phenomenon of school bullying. Because the perpetrators and victims are generally very young, the incidents of school bullying are more likely to be regarded as the small conflict between classmates' or 'a little joke between children', thus ignoring the fact that someone is being harmed by others, and teachers often may not actively seek solutions [2]. This article uses literature review research methods to explain the harm of school bullying to students. Understanding the views and attitudes of some schools on school bullying incidents through case analysis, using schools and teachers as a starting point, and attempting to extract suggestions from existing bullying prevention policies to increase people's attention to school bullying. Suppress and reduce the frequency of related incidents.

\section{HARMFULNESS OF SCHOOL BULLYING}

The phenomenon of school bullying has been endangering students who have participated in bullying in all of its forms for a long time. It is not limited to causing physical harm to the victim [3]. Studies have shown that an unsafe school environment may be harmful: 
It has a negative psychological impact on students [4], on the school atmosphere and students' performance [5], and may also have a certain impact on the dropout rate of students. Dropouts may have some connection to the harm from peers, It is related to the harm of being in a bullied environment, which leads to a decline in academic performance, and then in turn leads to a student's decision to drop out [6]. They believe that frequent bullying will make a school's atmosphere worse, students may develop resistance and avoidance towards the school, thus prompting students to drop out of school and leave school early. This phenomenon will even spread to other ordinary students in the school, causing the impact of dropout to spread throughout the school.

\section{EXAMPLE FOR THE IMPACT OF BULLYING IN SCHOOLS}

Konishi et al (2010) analyzed a data sample of the International Student Assessment Program (PISA) in 2003. The sample collected the personal data, math, and reading scores of 13,748 15-year-old girls and 13,469 boys from all over the world, and also evaluated 1087 school principals. Konishi et al(2010) found that school bullying has a negative impact on student performance. The model [5] shows that there is an obvious negative correlation between the frequency of school bullying incidents and the students' math scores, which indicates that: the higher the bullying atmosphere, the lower the students' scores. At the same time, they also found through the model that there is a positive correlation between student-level variables and student performance. Students who maintain active contact with teachers will have better grades and bullying. In other words, in a school environment, the identity of a teacher can play a role in buffering and reducing school bullying incidents. This study shows the possible positive effects of teachers on school bullying, but it does not take into account the attitudes of teachers to school bullying. In the whole school environment, the school, teachers, and students are the three important components. As managers and guides of students' thoughts and behaviors, teachers and schools have more opportunities to intervene in school affairs [7], and will have a greater influence on school bullyingrelated incidents. At this time, teachers The attitude of the group and the school will become more important.

\begin{tabular}{|c|c|c|c|c|}
\hline \multirow[b]{2}{*}{ Parameter } & \multicolumn{2}{|c|}{ Math achievement } & \multicolumn{2}{|c|}{ Reading achievement } \\
\hline & $\begin{array}{l}\text { Model 2: Only } \\
\text { Level-I predictor }\end{array}$ & $\begin{array}{l}\text { Model 3: Both Level-I \& } \\
\text { Level-2 predictors }\end{array}$ & $\begin{array}{l}\text { Model 2: Only } \\
\text { Level-I predictor }\end{array}$ & $\begin{array}{l}\text { Model 3: Both Level-I \& } \\
\text { Level-2 predictors }\end{array}$ \\
\hline \multicolumn{5}{|l|}{ Fixed effects } \\
\hline Intercept & $520.21 * * *(1.00)$ & $547.46 * * *(3.84)$ & $514.97 * * * *(0.97)$ & $537.06 * * *(3.73)$ \\
\hline S-T connectedness & $10.56 * * *(1.56)$ & $7.43 * 1 \%$ (1.73) & $14.34 * \%(0.98)$ & $10.22 * * * *(1.72)$ \\
\hline Bullying & & $-14.25 * * *(2.07)$ & & $-11.59 * * *(2.00)$ \\
\hline Bullying $\times$ S-T connectedness & & $1.70 *(0.83)$ & & $2.25 * *(0.82)$ \\
\hline \multicolumn{5}{|l|}{ Random effects } \\
\hline Level-I variance & $728.68 * * *(33.00)$ & $302.29 * * *(17.14)$ & $683.53 * * *(31.39)$ & $279.64 * * *(16.11)$ \\
\hline Level-2 variance & $5577.79 * * *(50.51)$ & $5622.00 * * *(50.75)$ & $5511.25 * * *(49.90)$ & $5548.8 \mathrm{I} * * *(50.10)$ \\
\hline$R^{2}$ Index & .53 & .81 & .54 & .81 \\
\hline Goodness-of-fit (Deviance) & 307532.8 & 296888.3 & 307138.1 & 296496.6 \\
\hline
\end{tabular}

Note: The values within parentheses denote standard errors. $* p<.05 . * * p<.01 . * * *$ < $<.001$.

Figure 1. Multilevel Estimates on Entire Sample for Research Question 2: Models for Math and Reading, quoted from [9].

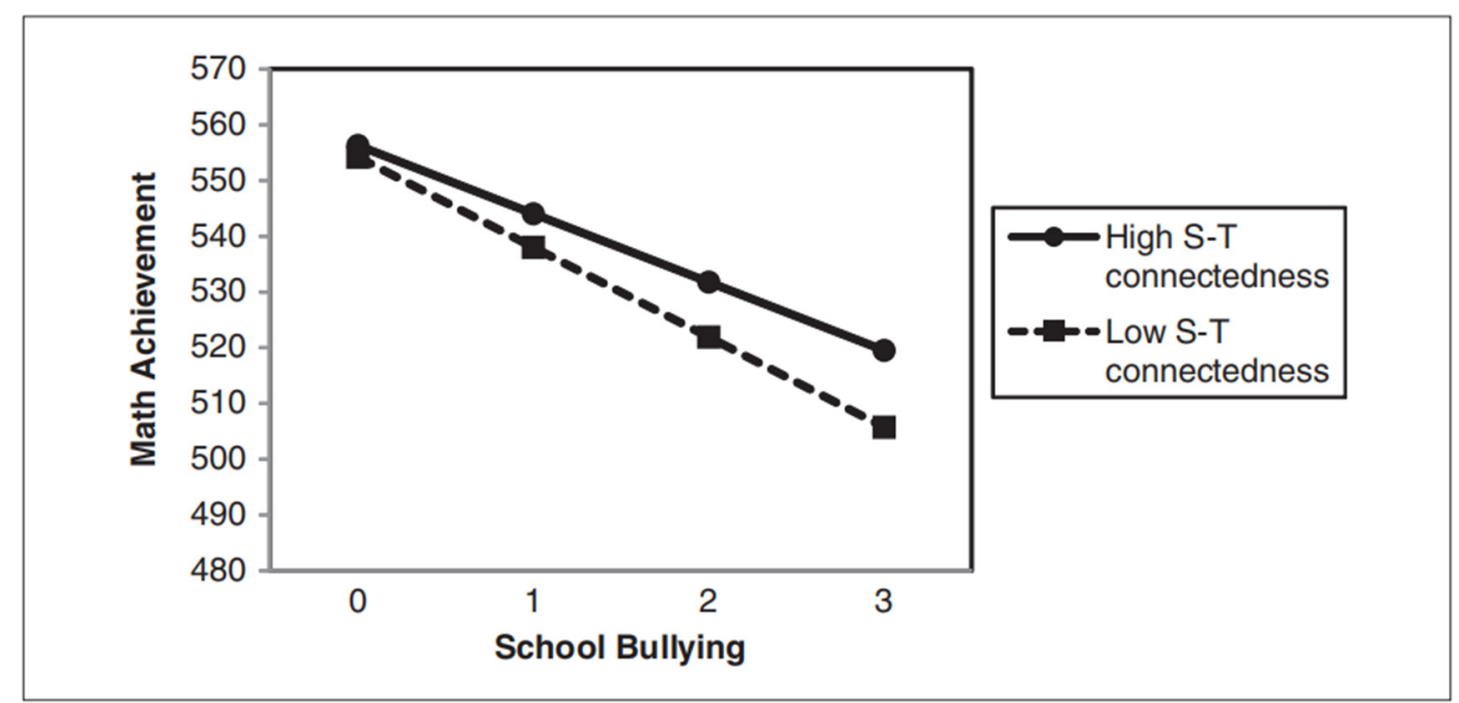

Figure 2. Plotted simple slopes for the relationship of bullying to math achievement at 2 levels of S-T connectedness, quoted from [5]. 


\section{THE REACTION OF TEACHERS AND STUDENTS}

School bullying is invisible, and the higher frequency of bullying behaviors happened in places where teachers can't notice [8]. To a certain extent, some teachers' laissez-faire and tolerant attitude towards bullying have indirectly increased the psychological distance between students and teachers, which may make students more willing to choose their peers as the object of confession after being bullied [9]. Therefore, an important step in reducing school bullying is to make teachers fully aware of bullying. The severity of the bullying phenomenon strengthens the ability to recognize violent behavior and management methods and increases the frequency of teacher intervention [10]. In addition to bullies and victims, school bullying will also affect bystanders to a large extent As a result, the impact of violent incidents spread throughout the school environment [11]. Most of the sense of security that students gain during the enrollment period will be given by teachers and the school atmosphere. Therefore, if the overall school atmosphere starts to become unfavorable Development, then the life and academic performance of bystanders may also have an impact, which will cause the overall learning level of the school to begin to decline. Although many teachers think that they often intervene in bullying incidents, but judging from the behavior of some teachers, the phenomenon of bullying among students is still not detectable by teachers. The studies have shown that teachers successfully detect and intervene in school bullies. But these are only a few incidents of bullying had been solved, and they are mainly near the teachers where teachers often walk around [12]. He found out that the extent of teachers' discovery of bullying incidents is often more restricted on the open playground. In addition, in an Israeli event In a national survey of school violence, Berkowitz (2014) found that students gain a sense of security through the behavior of teachers. When teachers view harmful incidents such as bullying in a positive manner, the students will feel safer. At the same time, he learned from his conclusions that teachers' and students' perceptions of school bullying incidents vary from person to person. The results of the study show that students who have not been exposed to bullying incidents are more likely to receive positive signals from surrounding students and teachers. Conversely, students who have experienced bullying, whether they are bullies or victims, are relatively unable to receive positive reactions from others. Craig et al (2011) conducted a questionnaire survey on 750 students participating in pre-service teacher education at a university in order to address the issue of teachers' awareness of school bullying. The results show that pre-service teachers who have witnessed or personally experienced the bullying process have a stronger perception of the severity of the bullying incident, and there is a significant positive correlation between those two things. This shows that teachers with more relevant experiences are more sensitive to bullying incidents, and psychologically they will pay more attention to the occurrence of such incidents. They may generally identify the red flags of bullying more quickly and have more confidence and ability in prevention and timely management. In addition, Craig et al(2011) compared pre-service teachers trained in violence prevention with other teachers and found that pre-service teachers who have received training are generally better than other pre-service teachers in all aspects of handling bullying. It shows that the training to prevent bullying can help change teachers' emphasis on bullying, make up for the lack of relevant experience to a certain extent, and may increase the degree of intervention of teachers in school bullying.

\section{CURRENT POLICIES ON BULLYING IN SCHOOLS}

Due to the serious harm caused by school bullying to young people, since about the 1970s, countries and scholars around the world have begun to invest in the prevention of school bullying, and it also has started to actively formulate anti-bullying policies [13]. Among them, in the United States, the public has begun to pay more and more attention to the problem of school bullying, which led to the passing of anti-bullying laws by all 50 states [14]. However, the laws in some states in the United States do not clearly define the meaning of bullying, which may indicate that bullying in the law may refer to aggressive behaviors that trigger serious conflicts among students [15]. Through their suggestions, this implementation of the policy also requires schools and teachers to intervene and cooperate with the bullying incident to promote the policy. At the same time, schools in some countries and regions have adopted a zerotolerance attitude towards school bullying incidents, which is means if a bullying incident is found by teachers, The bullier will be severely punished [13]. The advantage of intervention is that once school administrators are aware of the problem, the bullying incidents may usually be solved directly. However, actual investigations revealed that the definition of bullying in the Zero Tolerance Policy is still controversial [13]. Some faculty members have abused the policy too much, and it leads that some students' minor violations being punished severely. Some researchers believe that overly arbitrary solutions may intensify conflicts among students, and are also not conducive to repairing the negative impact of school bullying on schools and students [10]. Before using the zero-tolerance policy, school administrators and faculty members should have a clear understanding of bullying behavior. The violence prevention training for pre-service teachers proposed in Craig et al (2011) can change teachers' understanding of bullying to a certain extent and enhance teachers' independent judgment ability. I think this training method may effectively 
promote the birth of the system related to mitigating circumstances in the zero-tolerance policy and make the punishment results more in line with the actual violations of students. I suggest adding courses on the identification and prevention of school violence to teachers' pre-service training, and refining the treatment measures for different school plots in the zero-tolerance policy to make the policy more humanized.

\section{DISCUSSION}

The previous research cases show that the identity of teachers can buffer and reduce school bullying in the school environment. But at the same time, school bullying is hidden and may not be found by teachers and schools in time. The premise of preventing further harm from school bullying is to find out the existence of campus bullying, at present, only a few incidents have been successfully found and intervened by teachers. In fact, there are still a large number of school bullying incidents that have not been found, which is related to the location of the incident and the attention of teachers, and teachers' unclear definition of school bullying. In most cases, the bullying often occurs in places that are not easy to be noticed by people, such as toilets, sundry rooms, hidden alleys, bullying incidents tend to occur more frequently in blind spots of observation and lack monitoring in the school and surrounding environment [16]. The choice of these places can help bullies better hide the behavior of hurting others, so as to escape the possible punishment. Therefore, we need to strengthen monitoring in the public environment inside and outside the school, so that teachers can improve their attention to remote places, reduce the places conducive to school bullying, and increase the exposure probability of bullying events.

In addition, teachers also need to increase their understanding of school bullying. Many people's definition of school bullying only exists in a vague definition standard, and lack of sufficient resolution of bullying may lead to two situations: one is to treat the bullying that is happening at present as normal game behavior between students and ignore them; The other is that teachers and schools overreact and severely punish some minor violations as bullying. If the zero-tolerance policy is used as a punishment in the second case, it may be difficult to have a positive impact on the school atmosphere. Therefore, before formulating prevention and control measures, we need to establish a clear boundary for the phenomenon of school bullying, so as to distinguish between students' normal play and school bullying, so that people can face up to the phenomenon of bullying and prevent the abuse of the word school bullying [17].

\section{CONCLUSION}

This article mainly revolves around a review of the school and teachers' response to school bullying incidents. From various research cases, we find that education departments, schools, and teachers at this stage need to deepen their understanding of school bullying and increase their experience in handling related incidents. This can be practiced through simulation training. On the other side, the policy on school bullying is still immature. At this policy, there is no specific scope for bullying behavior, more investigation and research are needed to gradually improve the existing anti-bullying policies. The awareness of school bullying promotes positive reactions among students and faculty members. While sanctioning bullying behavior, it also offers condolences and compensation to victims and strives to improve the negative impact of bullying on the school atmosphere and make more students can study at ease. The disadvantage of this article is that it only focuses on students and teachers to summarize and discuss the phenomenon of school bullying, ignoring the role and possibility of student families in related incidents. School bullying also needs to consider all aspects of the impact of the family environment on students, which may play a key role in the role positioning of the bully, the victim, and the bystander in the bullying incident. Nowadays, school bullying is still a serious problem in schools. We need to continuously improve related intervention policies and treatment methods to ensure that young people can grow up healthy in a safe school environment. In the next study, I will focus on the cognition and response of students' families to school bullying, explore the extent to which parents generally define events as school bullying, whether becoming victims or perpetrators is related to their growing family environment, and find a breakthrough to reduce school bullying from the perspective of family.

\section{ACKNOWLEDGMENT}

First of all, I would like to thank Prof. Gearon and Chenkai Chi for their valuable advice in developing the topic, narrowing the topic, and designing the structure of my paper. In the research of this topic, the two teachers recommended many good books and writing methods to me. I also want to thank Teacher Yufan Huang, who has provided me with a lot of help in the subsequent modification and optimization of the paper and pointed out many shortcomings in my writing, which has benefited me a lot. I would like to express my heartfelt thanks to the three teachers again.

\section{REFERENCES}

[1] Xu, X. (2015). What you should know about campus bullying. Shanghai Education (35), 22-23. doi:CNKI:SUN:SHJZ.0.2015-35-013. 
[2] Zhou, Y. (2017). The countryside junior middle school campus bullying phenomena, causes and countermeasures of research (a master's degree thesis, northwestern university). https://kns.cnki.net/KCMS/detail/detail.aspx?dbna $\mathrm{me}=\mathrm{CMFD} 201801 \&$ filename $=10172$ 71192.nh

[3] Yibo, Zhou. (2018). Types and characteristics of high school violence. Red Son, 000(036), 69.

[4] Jiang, Y. (2018). Middle school bullying attitude questionnaire compiled with research and intervention study (a master's degree thesis, chongqing normal university). https://kns.cnki.net/KCMS/detail/detail.aspx?dbna $\mathrm{me}=\mathrm{CMFD} 201802 \&$ filename $=1018136844 . \mathrm{nh}$

[5] Konishi, C., Hymel, S., Zumbo, B. D., \& Li, Z. (2010). Do school bullying and student-teacher relationships matter for academic achievement? A multilevel analysis. Canadian journal of school psychology, 25(1), 19-39.

[6] Cornell, D., Gregory, A., Huang, F., \& Fan, X. (2013). Perceived prevalence of teasing and bullying predicts high school dropout rates. Journal of educational psychology, 105(1), 138.

[7] Zhang, J., \& Wang, J. (2001). The impact of teacher behavior intervention on student health education. Chinese Journal of School Health, 22(6), 544-544. DOI: $10.3969 /$ j.issn.1000-9817.2001.06.029

[8] Craig, K., Bell, D., \& Leschied, A. (2011). Pre-service teachers' knowledge and attitudes regarding schoolbased bullying. Canadian Journal of Education/Revue canadienne de l'éducation, 34(2), 21-33.

[9] $\mathrm{Wu}$, J. (2016). Investigation and intervention of bullying behavior in primary schools. Inner Mongolia Normal University. http://cdmd.cnki.com.cn/article/cdmd-101351016171645.htm

[10] Coloroso, B. (2002). The bully, the bullied, and the bystander. Toronto, ON: Harper Collins.

[11] Berkowitz, R. (2014). Student and teacher responses to violence in school: The divergent views of bullies, victims, and bully-victims. School Psychology International, 35(5), 485503. https://doi.org/10.1177/0143034313511012

[12] Pellegrini, A. D. (1998). Bullies and victims in school: A review and call for research. Journal of Applied Developmental Psychology, 19, 165-176, doi: 10.1016/S0193-3973(99)80034-3.
[13] Roberge, G. D. (2012). From zero tolerance to early intervention: The evolution of school anti-bullying policy. Journal of Education Policy, 1, 1-6.

[14] U.S. Department of Health and Human Services. (2015). Bullying policies and laws. from http://www.stopbullying.gov/laws/index.html

[15] Hall, W. J., \& Chapman, M. V. (2018). The role of school context in implementing a statewide antibullying policy and protecting students. Educational policy, 32(4), 507-539.

[16] Wang, S. (2019). Analysis of the relationship between landscape environment and campus bullying. Intelligence (24), 194-195. Doi: CNKI: Sun: caiz. 0.2019-24-182.

[17] Zhang, Y., Li, B., \& Wang, H. (2020). Prevention and treatment of school bullying: Accurate definition and source management. Journal of Beijing Vocational College of Political Science and Law (04),47-52. doi:CNKI:SUN:BZGX.0.2020-04008 . 